\title{
Reverse transcription loop-mediated isothermal amplification assay for rapid detection of Bovine Rotavirus
}

Zhixun Xie ${ }^{1,2^{*}}$, Qing Fan ${ }^{1,2}$, Jiabo Liu ${ }^{1,2}$, Yaoshan Pang ${ }^{1,2}$, Xianwen Deng ${ }^{1,2}$, Zhiqin Xie ${ }^{1,2}$, Xie Liji ${ }^{1,2}$ and Mazhar I Khan ${ }^{3^{*}}$

\begin{abstract}
Background: Bovine rotavirus (BRV) infection is common in young calves. This viral infection causes acute diarrhea leading to death. Rapid identification of infected calves is essential to control BRV successfully. Therefore development of simple, highly specific, and sensitive detection method for BRV is needed.

Results: A reverse transcription loop-mediated isothermal amplification (RT-LAMP) assay was developed and optimized for rapid detection of BRV. Specific primer sets were designed to target the sequences of the VP6 gene of the neonatal calf diarrhea virus (NCDV) strain of BRV. The RT-LAMP assay was performed in a water bath for 60 minutes at $63^{\circ} \mathrm{C}$, and the amplification products were visualized either directly or under ultraviolet light. This BRV specific RT-LAMP assay could detect 3.32 copies of subtype A BRV. No cross-reactions were detected with other bovine pathogens. The ability of RT-LAMP to detect bovine rotavirus was further evaluated with 88 bovine rectal swab samples. Twenty-nine of these samples were found to be positive for BRV using RT-LAMP. The BRV-specificRT-LAMP results were also confirmed by real-time RT-PCR assay.
\end{abstract}

Conclusions: The bovine rotavirus-specific RT-LAMP assay was highly sensitive and holds promise as a prompt and simple diagnostic method for the detection of group A bovine rotavirus infection in young calves.

Keywords: BRV, VP6 gene, Reverse transcription loop-mediated isothermal amplification (RT-LAMP)

\section{Background}

Rotavirus, a double-stranded RNA virus, is a member of the family Reoviridae. Rotaviruses are classified into six, or possibly seven serogroups [1,2]. Rotavirus infections with group $\mathrm{A}$ are the major cause of acute diarrhea among newborn animals and humans leading to death $[3,4]$. Identification of infected calves, in combination with a proper vaccination program, is essential to control BRV successfully. The current methods for the detection and characterization of BRV, which include virus isolation, immunoassay, electron microscopy, and nucleic acid hybridization, are time consuming and

\footnotetext{
* Correspondence: xiezhixun@126.com; mazhar.khan@uconn.edu

'Department of Biotechnology, Guangxi Veterinary Research Institute, 51 You Ai Road, Nanning, Guangxi 530001, China

${ }^{3}$ Department of Pathobiology \& Veterinary Science, University of Connecticut, Storrs, CT 06260-3089, USA

Full list of author information is available at the end of the article
}

laborious [5-7]. On the other hand, the polymerase chain reaction (PCR) has been used successfully for the detection and characterization of BRV [8-10]. Unfortunately, PCR assays require sophisticated equipment, which is costly to maintain, and must be performed in specialized laboratories (Additional file 1: Figure S1 and S2).

The recently described loop-mediated isothermal amplification (LAMP) can amplify specific target DNA sequences with high sensitivity and can be completed within 60 minutes under isothermal conditions without the need of a thermal cycler and specialized laboratory [11]. This technique eliminates the heat denaturation step for DNA synthesis used in conventional PCR, and relies instead on auto-cycling strand displacement DNA synthesis achieved by a DNA polymerase with high strand displacement activity and a set of two specially designed inner and two outer primers. Another important feature of LAMP is a resulting color change

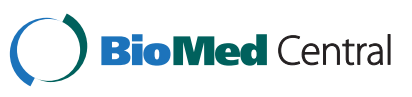


following the addition of a fluorescent dye, making it visible to the naked eye. The LAMP assay has been used successfully to detect many pathogens [12-19] and in using reverse transcriptase, it has been further adapted for the detection of RNA viruses [15,16]. The objective of the study reported here was to develop and optimize the reverse transcription LAMP (RT-LAMP) assay for the detection of group A BRV in calves.

\section{Methods}

\section{Cells and Virus Strains}

Table 1 lists the pathogen strains used in this study and describes the following: ten group A BRV strains, five other bovine pathogens other than BRV, four negative controls, three normal bovines rectal swab samples (one each from normal bovine nasal mucus and blood sample). Nasal mucus swabs and blood samples were taken from all bovine following routine pre slaughter examination for the normal animals to be slaughter. The collection of these samples could be considered as part of regular and routine examination, therefore no official review and approval of the Guangxi Veterinary Research Institute was needed. The viruses were propagated using rhesus monkey epithelial cell line (MA-104) and grown in Eagle's minimal essential medium (MEM) according to previously described methods [6]. MEM was supplemented with $10 \%$ fetal calf serum free from BRV and BRV antibodies (Shijiqing, China). The BRV strains were

Table 1 Pathogens used and RT-LAMP assay results

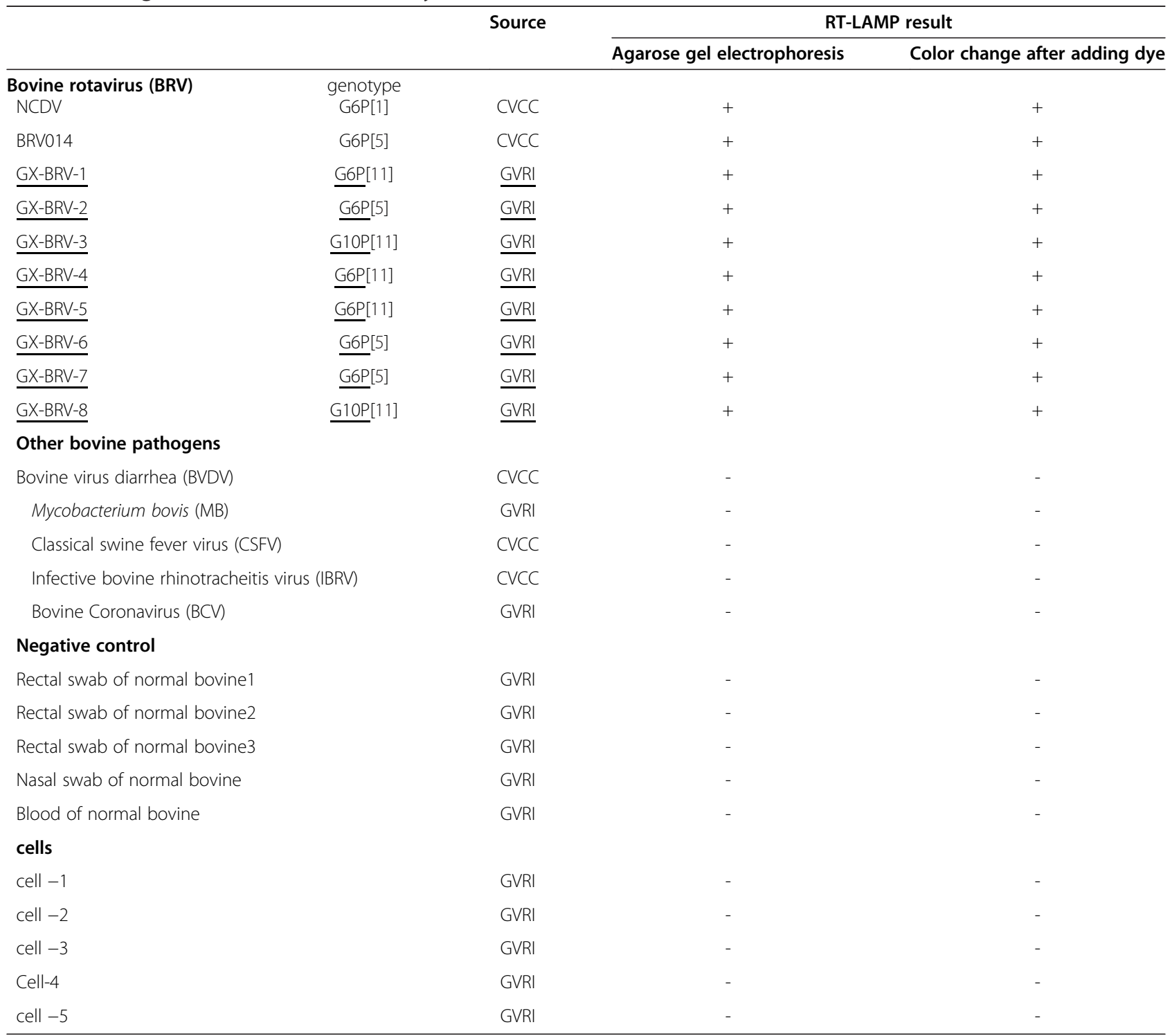

CVCC $=$ China Veterinary Culture Collection Center.

GVRI = Guangxi Veterinary Research Institute.

Positive $=+$; Negative $=-$. 
titrated by plaque assay in MA-104 cells in accordance to the published protocols $[6,16]$.

\section{DNA/RNA Extraction}

Genomic viral RNA, which includes BRV and other bovine virus strains from sample cultures, was extracted from infected MA-104 cell culture supernatant, as well as from swab sample cells from normal bovine using the TRIZOL RNA extraction kit in accordance with the manufacturer's protocol (Invitrogen, Carlsbad, CA, USA). Mycobacterium DNA was extracted using phenol: chloroform isoamyl alcohol (1:1:24 v/v) according to the Gibco BRL manufacturer's protocol (Gibco BRL, Grand Island, New York, USA). All nucleic acid samples were stored at $-70^{\circ} \mathrm{C}$ until use.

\section{Design of group A specific BRV RT-LAMP primers}

Primer design for Group A specific bovine rotavirus- RTLAMP was based on the published sequence of strain neonatal calf diarrhea virus (NCDV) (GenBank, accession no. K02254.1). The NCDV sequence was aligned with the available sequences of 21 isolates (Figure 1 a \& b) to identify the conserved regions using Primer Explored V4 soft ware available from: http://primerexplorer.jp/e/. A set of six primers comprised of two outer, two inner, and two loop primers was designed and is shown in Table 2. The inner primers, which are known as the forward inner primer (FIP) and the backward inner primer (BIP), each have two distinct sequences corresponding to the sense and antisense sequences of the target, one for priming the first stage, and the other for self-priming in later stages in the reaction. FIP contains F1c (complementary to F1), and the F2 sequence. BIP contains the B1c sequence (complementary to B1), and the $\mathrm{B} 2$ sequence. The outer primers (F3 and B3) were used in the initial steps of LAMP reactions, but later during the isothermal cycling only the inner primers were used for strand displacement DNA synthesis. Two additional loop primers (loopF and loopB) were designed to accelerate the amplification reaction as described [18]. The sequences of the selected primers were compared to VP6 gene sequences [20-22]. All the primers were synthesized and purified by Invitrogen Inc (Guangzhou, China).

\section{Real-time RT-PCR}

The sensitivity of the RT-LAMP method was compared to real-time RT-PCR using the two primers and one of the following probes: F5 (5'- TCATTTCAGTTGATGAGAC CACC -3'), F6 (5'- ATTCAATTCTAAGCGTGAGTCTAC -3'), or HEX-AATATGACACCAGCGGTAGCGGCBHQ1. This real time RT-PCR amplifies a 112-bp target sequence of the VP6 gene of group A BRV [10]. Real-time RT-PCR amplification was carried out using the Real-time one step RT-PCR Kit (Takara, Dalian, China) as described in previously published protocol (10). After the real-time RT-PCR was performed, cycle threshold (CT) was manually setup to reflect the best kinetic PCR parameters, such that any nonspecific amplification in reaction could be analyzed.

\section{Optimization of the RT-LAMP condition}

The RT-LAMP assay was optimized using various concentrations of primers, buffers, salt and RNA/DNA templates for positive and negative controls. The reaction mixture was optimized to $25 \mathrm{ul}$, containing primers in various concentrations, $1.4 \mathrm{mM}$ of each deoxyribonucleotide triphosphate, $0.8 \mathrm{M}$ of betaine (Sigma Chemical Co., Beijing, China), $2.5 \mathrm{ul}$ of $10 \times$ Thermo buffer, $8 \mathrm{mM}$ $\mathrm{MgSO} 4,8 \mathrm{U}$ of Bst DNA polymerase (large fragment; New England Biolabs), 0.125U of enhanced Avian myeloblastosis virus reverse transcriptase, and $2 \mathrm{ul}$ of the extracted target RNA. To determine the optimal duration for the RT-LAMP assay, the primer and reverse transcribed sample mixtures were incubated in a $63^{\circ} \mathrm{C}$ water bath for $20,40,60$, and 80 minutes. At the end of each incubation period, the reaction was terminated by heating at $80^{\circ} \mathrm{C}$ for 5 minutes. The reaction temperature was optimized using $61^{\circ} \mathrm{C}, 62^{\circ} \mathrm{C}, 63^{\circ} \mathrm{C}$, and $64^{\circ} \mathrm{C}$.

\section{Analysis of RT-LAMP product}

In order to analyze the amplified products, three detection methods were evaluated. First, turbidity: the accumulation of magnesium pyrophosphate, a byproduct of the DNA amplification reaction, increases the turbidity of the sample. Turbidity was evaluated by visual inspection of the samples, comparing them to a negative control sample. Second, color change: $1 \mathrm{ml}$ of $10,000 \times$ SYBR Green I nucleic acid stain was added to the tube after the reaction. Samples turning yellowgreen were considered positive, while samples turning orange were negative. Samples showing fluorescence under an ultraviolet hand lamp at a $365-\mathrm{nm}$ wavelength were considered positive as described previously [12]. Samples were compared with a negative control to account for background fluorescence. Third, gel electrophoresis: run on a $1 \%$ agarose gel, RT-LAMP reaction end product yields a combination of DNA fragments of varying sizes [11]. Therefore, the presence of a smear or a pattern of multiple bands of different molecular weights indicates a positive result. A molecular marker was used to estimate amplified product size.

Lastly, a restriction enzyme analysis: EcoRI and EcoRV restriction of the RT-LAMP product confirms reaction specificity [14]. Briefly, digestion reactions were performed using $3 \mathrm{ul}$ of RT-LAMP product with $12 \mathrm{U}$ of restriction enzyme in $25 \mathrm{ul}$ total volume. The size of the digested fragments was estimated by agarose gel electrophoresis as described [19]. 


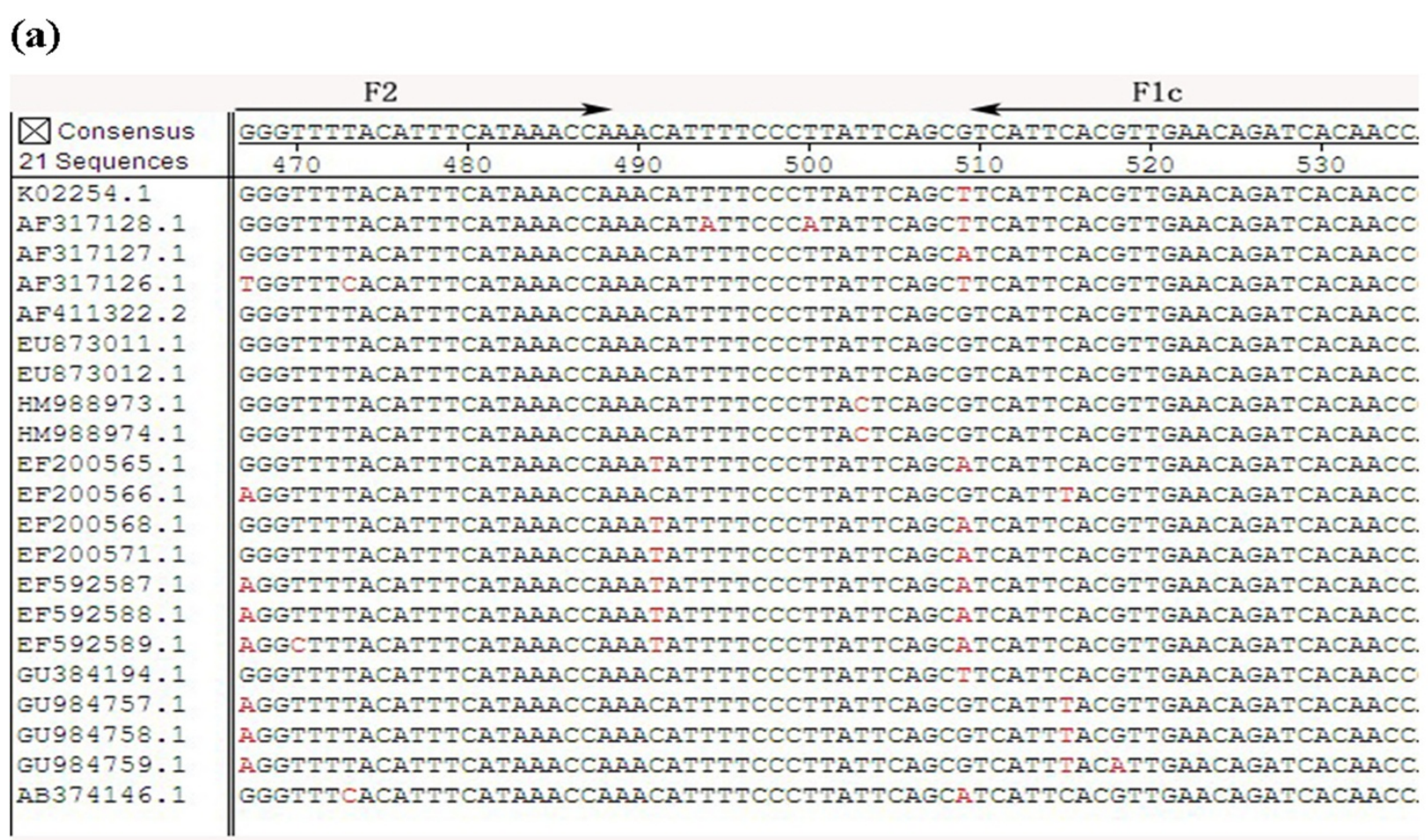

\section{(b)}

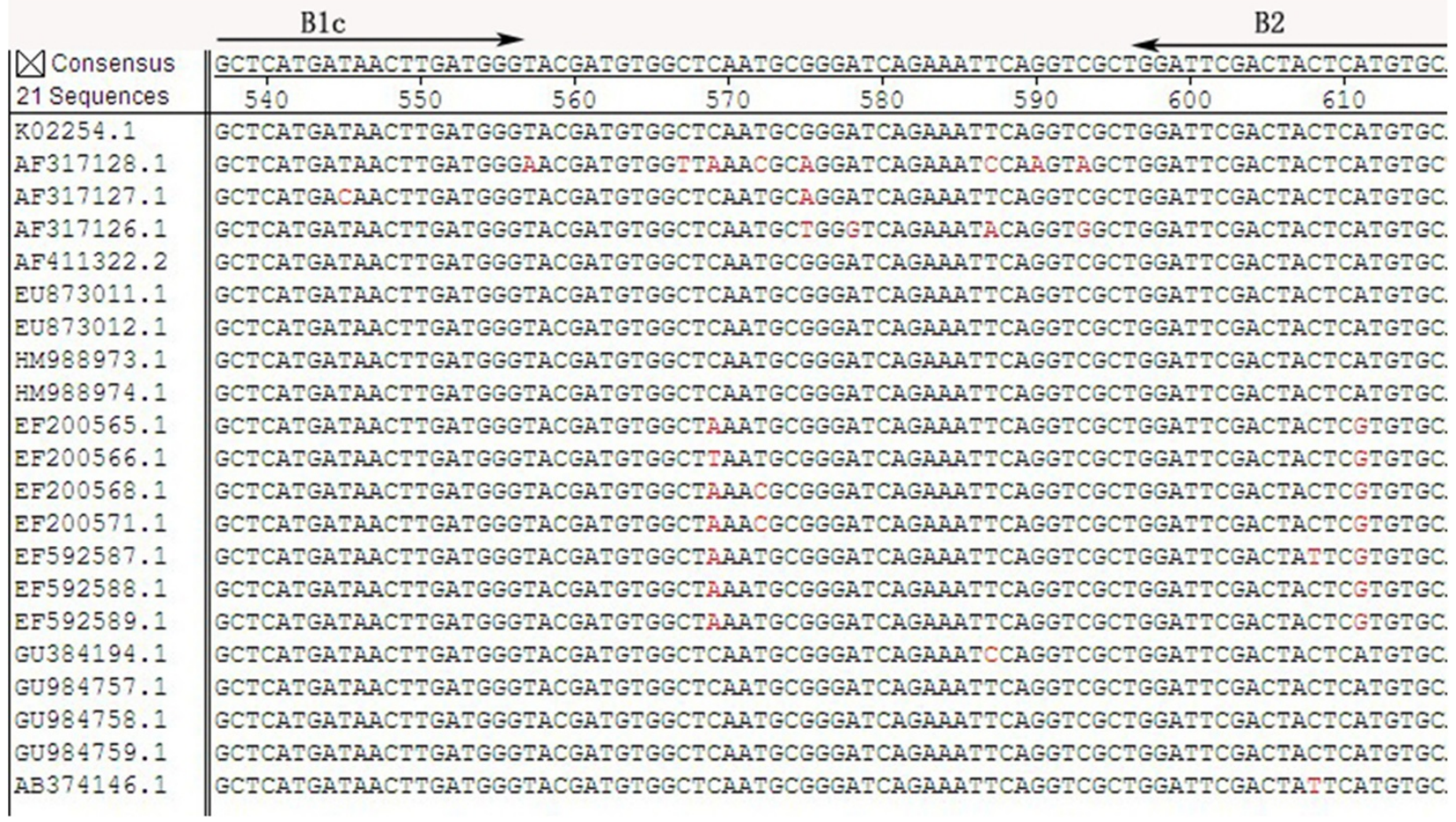

Figure 1 ( $\mathbf{a}$ and $\mathbf{b})$. Multiple sequence alignment of BRV VP6 genes. 
Table 2 Details of oligonucleotide primers used for RT-LAMP assay

\begin{tabular}{llc}
\hline Primer name & sequence $\left(5^{\prime}\right.$-3') & Genome position \\
\hline FIP $_{\mathrm{a}}=\mathrm{F} 2+\mathrm{F} 1 \mathrm{C}$ & GTTGTGATCTGTTCAACGTGAATGA-gaattc-GGGTTTACATTTCATAAACCAA & F1c,510-534F2,467-489 \\
$\mathrm{BIP}_{\mathrm{b}}=\mathrm{B} 2+\mathrm{B} 1 \mathrm{C}$ & GCTCATGATAACTTGATGGG- gatatc-GCACATGAGTAGTCGAATCC & B1c,537-556B2,597-616 \\
F3 & TTGCAAAATAGAAGACAAAGAAC & $444-466$ \\
B3 & GTTGCGTATTAGCTGGCG & $625-642$ \\
LoopF & CTGAATAAGGGAAAATGTTGGTT & $483-507$ \\
loopB & GATGTGGCTCAATGCGGG & $560-577$ \\
\hline
\end{tabular}

Genome position according to the bovine rotavirus complete genome sequence (GenBank accession no. K02254.1).

${ }_{a}$ FIP is composed of F2 and F1c, and they are linked by a sequences of EcoRlof -gaattc-.

b BIP is composed of B2 and B1c, and they are linked by a sequences of EcoRV of -gatatc-

\section{Evaluation of RT-LAMP}

To evaluate specificity, the RT-LAMP test was performed on a panel of viral isolates from bovine's reference viruses, (Table 1). The panel included three rectal and one nasal swab samples from a normal bovine, one blood sample from a normal bovine, one cell sample (repeated five times) as a negative control, ten strains of $\mathrm{BRV}$, and five different bovine DNA and RNA pathogens (Table 1).

The detection limit of RT-LAMP was tested and compared with real-time RT-PCR using triplicate templates at identical concentration. RNA transcripts corresponding to the VP6 of NCDV strain were generated for use as standards in the analysis of sensitivity of the assay. Briefly, RNA was extracted from NCDV strain using the TRIZOL RNA extract reagent. The purified RNA was resuspended in distilled water and used in the RT-PCR reaction. The amplified product of VP6 was cloned into the pGM-T vector (TaKaRa, Dalian, China) according to the manufacturer's directions and sequenced to verify its identity. The recombinant plasmid pGM-T-VP6 was linearized by digestion with restriction enzyme NotI, gel purified, and used as a template with a Ribo Max T7 In Vitro Transcription System (Promega, Madison, Wisconsin, USA) according to the manufacturer's protocol. The length of RNA transcripts was verified by agarose gel electrophoresis. The RNA of VP6 was quantitated using UV spectrophotometry at $260 \mathrm{~nm}$, and calculated copy numbers were calculated from the concentration as described previously [20]. A series of 10-fold dilutions were used to test the assay's sensitivity of BRV RTLAMP (Figure 2).

\section{Detection of clinical specimen by RT-LAMP assay}

After validation studies, we determined the reliability of the group A specific BRV-RT-LAMP as a method of viral RNA detection for clinical specimens. Written informed consent was obtained from each participating farm owner. On participating farms, the veterinarian collected rectal swab samples from the calves. The rectal swab samples were taken from calves between 3 to
180 days age, and were considered as part of regular and routine clinical-diagnostic care. No official review and approval of Guangxi Veterinary Research Institute was needed. A total of 88 rectal swab samples were collected from calves with acute diarrhea from different dairy farms in the Guangxi province (Table 3). The samples were placed into $1 \mathrm{ml}$ of sterilized water, and processed as described previously [12]. BRV-specific RT-LAMP assay was performed as described above. The results of group A specific BRV RT-LAMP were compared with the results of BRV real-time RT-PCR. Restriction enzyme analysis of RT-LAMP products and its sequencing were used to assess the reliability of the methods for the rapid detection of BRV.

\section{Results}

The optimal protocol of RT-LAMP assay and inspection of products

Following standardization and optimization, the optimal ratio of primer (inner-outer-loop) concentrations for the RT-LAMP reaction was found to be 8:1:4 equivalents to 1.6, 0.2 and $0.8 \mathrm{mM}$. Gene amplification was detected by an increase in turbidity, as well as adding dye for color change indication (Figure 3). Restriction enzyme analysis performed with EcoRI and EcoRV on the RT-LAMP product validated no nonspecific reaction in RT-LAMP assay. The RT-LAMP assay amplified the 199-bp target sequence of the VP6 gene of BRV (Figure 4). For the reproducible sensitive and specific results of RT-LAMP assay, the optimal reaction time and incubation temperature was found to be 60 minutes at $63^{\circ} \mathrm{C}$.

\section{Specificity and Sensitivity of RT-LAMP assay}

The bovine rotavirus-specific RT-LAMP assay specifically amplified strains NCDV-014, and 8 Guangxi field bovine rotavirus strains, which have been isolated from the Guangxi dairy farms, and exhibits no cross-reactivity with other pathogens (Table 1). This specificity was confirmed by agarose gel electrophoresis (Figure 5) and a color change assay (Figure 3). We also determined the assay sensitivity using a 10-fold dilution series. The detection 


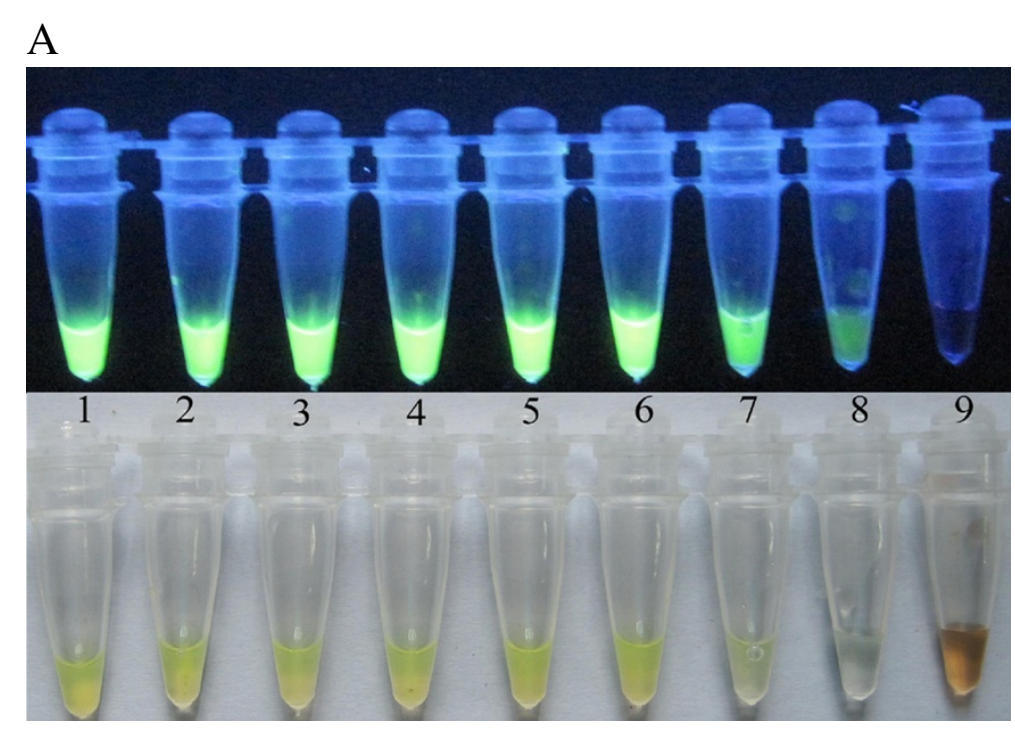

B

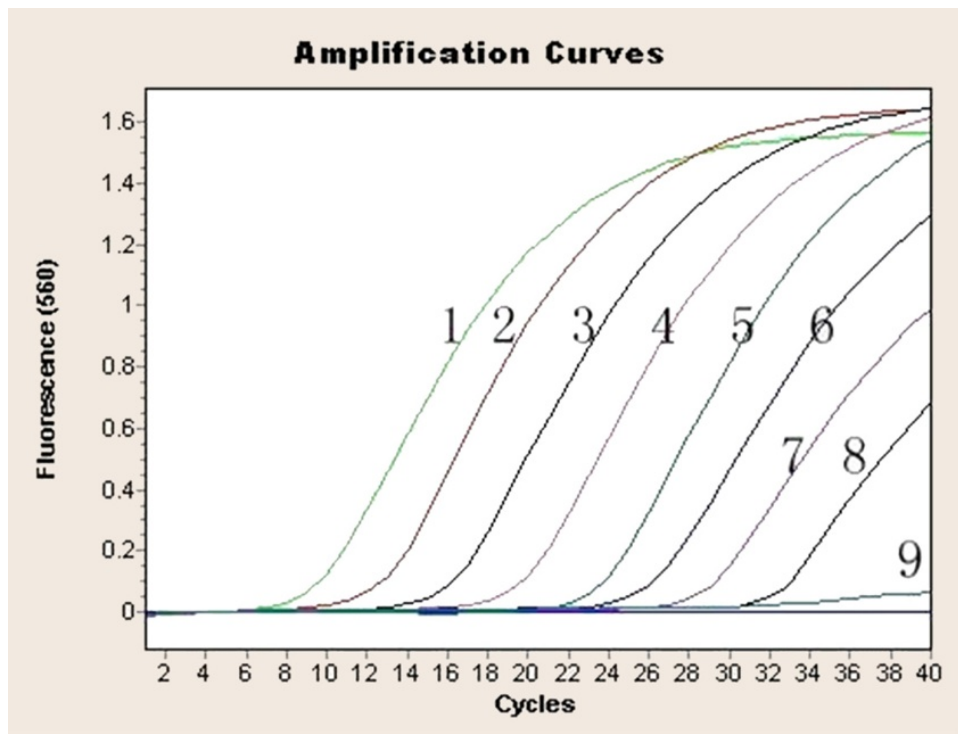

Figure 2 Sensitivity of RT-LAMP-and real-time RT-PCR. (A) RT-LAMP product; (B): real-time RT-PCR,1: $3.32 \times 10^{7} \mathrm{copies} /$ tube, $2: 3.32 \times 10^{6} \mathrm{copies} /$ tube, 3:3.32 $\times 10^{5} \mathrm{copies} /$ tube,4: $3.32 \times 10^{4} \mathrm{copies} /$ tube, 5: $3.32 \times 10^{3} \mathrm{copies} /$ tube; $3.32 \times 6: 10^{2} \mathrm{copies} /$ tube, $7: 3.32 \times 10^{1} \mathrm{copies} /$ tube, $8: 3.32 \times 10^{0} \mathrm{copies} /$ tube; $9: 3.32 \times 10^{-1}$ copies/tube.

Table 3 Comparison of real-time RT-PCR and RT-LAMP for the detection of BRV in clinical samples

\begin{tabular}{lllll}
\hline Location of samples & Number of Samples & \multicolumn{2}{c}{ Number of positive samples for assay } \\
\cline { 3 - 5 } & & Real-time RT-PCR & RT-LAMP & Sequencing \\
\hline Nanning & 24 & 7 & 3 & correct \\
Liuzhou & 15 & 3 & 3 & correct \\
Fangcheng & 10 & 3 & 5 & correct \\
Shangsi & 13 & 5 & 10 & correct \\
Guilin & 20 & 10 & 1 & correct \\
Hengxian & 16 & 1 & 29 & correct \\
Total & 88 & 29 & correct \\
\hline
\end{tabular}

${ }^{\mathrm{a}}$ RT-LAMP -positive samples were all confirmed to be BRV by sequencing the RT-LAMP- products restriction analysis of VP6 genes. 


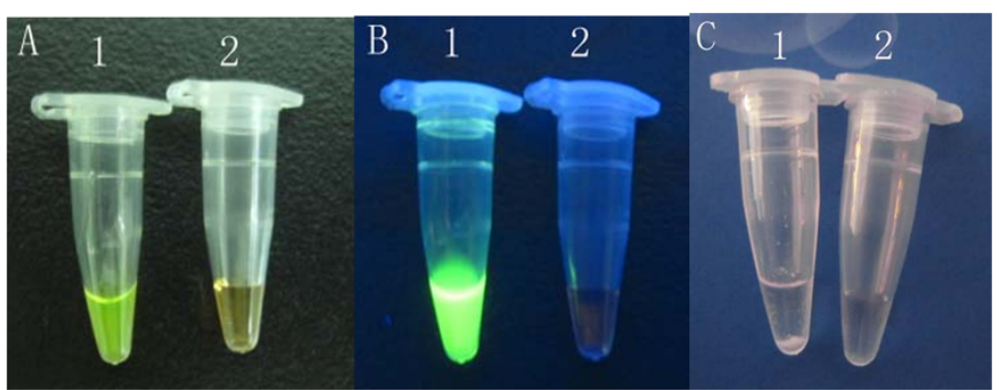

Figure 3 Detection of BRV RT-LAMP product. A: Fluorescent dye added seen without ultraviolet light, B: Fluorescent dye added seen with ultraviolet light, C: By turbidity with white sediment. 1: positive control sample; 2: negative control sample.

limit of RT-LAMP was 3.32 copies (Figure 2-A). Similarly, the detection limit of real-time RT-PCR analysis was 3.32 copies (Figure 2-B). The results indicate that RT-LAMP is as sensitive as real-time RT-PCR, both of which can detect 3.32 copies of bovine rotavirus VP6 gene.

\section{Evaluation of RT-LAMP assay with clinical samples}

In comparison with real-time RT-PCR, using the above described procedure with specific primers, 29 rectal swab samples (33.0\%) were found positive by both realtime RT-PCR analysis and RT-LAMP, and 59 (70\%) were found negative by both tests. As such, the coincidence of real-time RT-PCR and RT-LAMP was 100\%. However, RT-LAMP is a quicker, easier, and more cost efficient

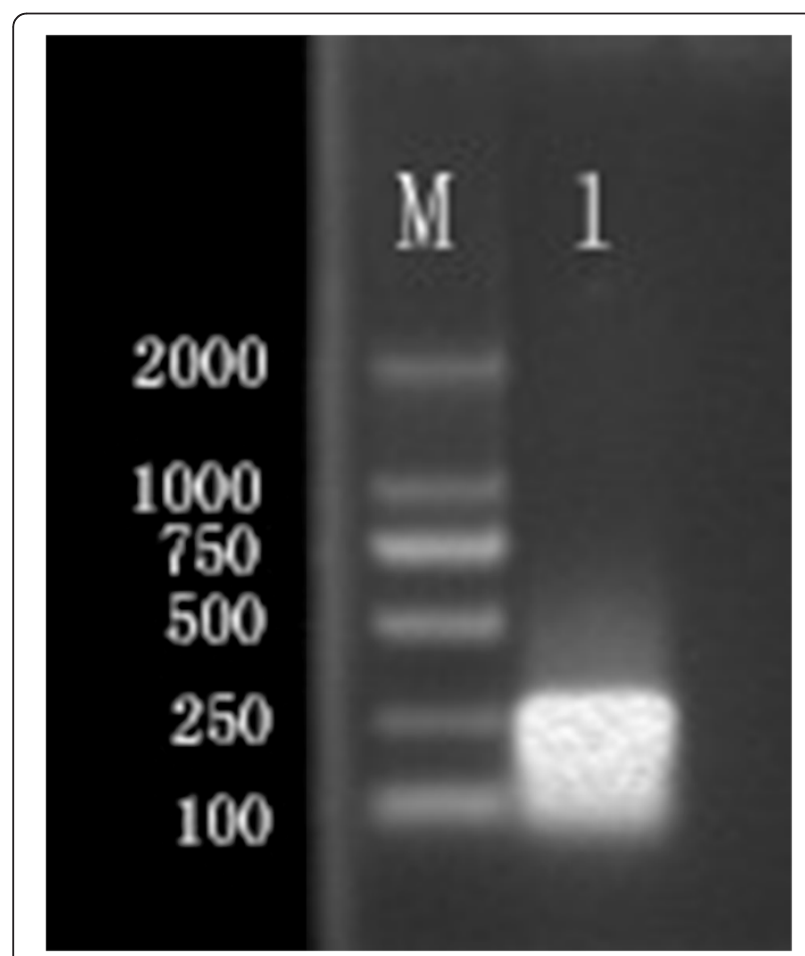

Figure 4 Restriction analysis of RT-RT-LAMP product. M. DNA marker; 1. RT-LAMP products digested with EcoRland EcoRV. method than real-time RT-PCR. Restriction enzyme revealed 199-bp target sequence of the VP6 gene of BRV, and sequencing analysis results showed that the clonal sequences of 29 samples were VP6 of BRV. The results indicated no nonspecific amplification in RT-LAMP reaction occurred (data not shown).

\section{Discussion}

The RT-LAMP was shown here to be specific and sensitive to detect rotavirus in rectal swab samples of calves with acute diarrhea. The BRV-specific RT-LAMP primers and real time probe were designed using VP6 genes sequencing of $21 \mathrm{BRV}$ isolates (Figure $1 \mathrm{a} \& \mathrm{~b}$ ) from the Genbank data. VP6 a group-specific gene of $\mathrm{BRV}$ is the most immunogenic viral protein and considered to be very conserved among group A BRV and suitable to use as conserved gene specific for BRV [21-23]. The RT-LAMP was determined to be specific, as no crossreactions were observed when other bovine pathogens were tested.

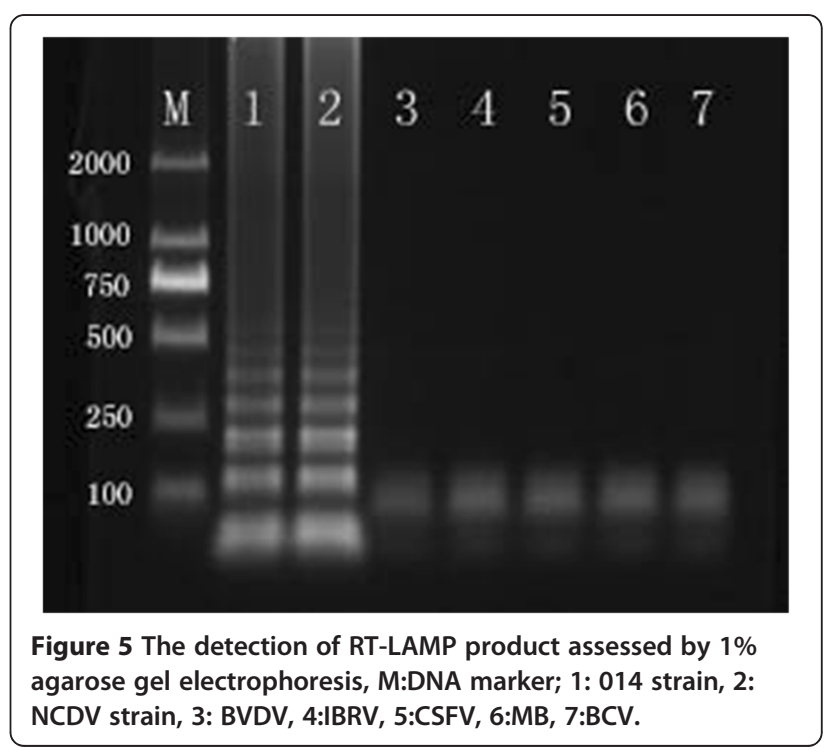


The RT-LAMP technique offers several advantages over PCR for the detection of bovine rotavirus RNA. Firstly, the RT-LAMP demonstrates high efficiency under isothermal conditions without a significant influence of non-target DNA and demonstrates sensitivity identical to that of real-time RT-PCR assays. Secondly, the RT- LAMP is easy to perform once the appropriate primers are selected and optimized. The reaction requires only four primers, a Bst DNA polymerase, and a temperature adjustable conventional laboratory water bath. Thirdly, the results of RT-LAMP are visible to the naked eye without the need for electrophoresis. This is attributable to recognition of the target sequence by six primers in the initial stage and by four primers during the later stages of the RTLAMP reaction. The RT-LAMP system possesses specificity in addition to high sensitivity and may be used in large-scale molecular surveys of BRV infections in the field.

Nevertheless, RT-LAMP is not without caveats: First, the main challenge in development of molecular tests for BRV is the large genetic heterogeneity of this virus [3.4]. This emphasizes the need for constant updating of primers of molecular diagnostic tests for BRV, with FIP and BIP being the most important primers in the entire assay, and they need to be conserved across many strains. Second, due to its high amplification production, the issue of potential cross-contamination problems needs to be addressed. We have added dye into the reaction system before the actual amplification in order to eliminate contamination.

It should be pointed out that in utilizing theVP6 gene target for the optimization of specific primers, we would expect this BRV RT-LAMP assay to meet the practical needs of BRV detection in the field around the world. While the RT-LAMP developed here needs to be validated against rotaviruses of groups $\mathrm{B}$ and $\mathrm{C}$ and other groups, these bovine rotavirus groups have not yet been identified in cattle in southern China. To the authors' knowledge, this is the first study that has explored the use of RT-LAMP technology in a diagnostic test for BRV. The test was simple, specific, and rapid; it was able to detect BRV from rectal swabs from BRVinfected calves.

\section{Conclusions}

In this study, the established RT-LAMP assay with high sensitivity and specificity was performed in a water bath within only 60 minutes, and the amplification results were visualized by the naked eye after adding a fluorescent reagent. The newly developed assay can be used as one important tool for detecting BRV in calves under field conditions with no need for specialized equipment.

\section{Additional file}

Additional file 1: Figure S1 and S2.

Competing interests

The authors declare that they have no competing interests.

\section{Authors' contributions}

ZXX, QF and MIK designed the experiments. QF and LJX prepared the RNA samples. QF designed the primers and optimized conditions of the RT-LAMP assay. JBL, YSP, XWD and ZQX carried out the experiments shown in Figures 3, 4, 5 and 2 and in Table 1. 2, 3.4 QF and MIK performed the data analysis and wrote the manuscript. All authors read and approved the final manuscript.

\section{Acknowledgements}

This research was supported by Guangxi Natural Science Foundation (2011GXNSFA018096), Guangxi Government Senior Scientist Foundation (2011B020).

\section{Author details}

${ }^{1}$ Department of Biotechnology, Guangxi Veterinary Research Institute, 51 You Ai Road, Nanning, Guangxi 530001, China. ${ }^{2}$ Guangxi Key Laboratory of Animal Vaccines and Diagnostics, 51 You Ai Road, Nanning, Guangxi 530001, China. ${ }^{3}$ Department of Pathobiology \& Veterinary Science, University of Connecticut, Storrs, CT 06260-3089, USA.

Received: 15 December 2011 Accepted: 29 June 2012

Published: 15 August 2012

\section{References}

1. Prasad BV, Chiu W: Structure of rotavirus. Curr Top Microbiol Immunol 1994, 185:9-29.

2. Pesavento JB, Crawford SE, Estes MK, Prasad BV: Rotavirus proteins: structure and assembly. Curr Top Microbiol Immunol 2006, 309:189-219.

3. Woode GN, Bridger JC, Jones JM, Flewett TH, Davies HA, Davis HA, White GB: Morphological and antigenic relationships between viruses (rotaviruses) from acutegastroenteritis in children, calves, piglets, mice, and foals. Infect Immun 1976, 14:804-810.

4. Kalica AR, Sereno MM, Wyatt RG, Mebus CA, Chanock RM, Kapikian AZ: Comparison of human and animal rotavirus strains by gel electrophoresis of viral RNA. Virol 1978, 87:247-255.

5. de Beer M, Peenze I, da Costa Mendes VM, Steele AD: Comparison of electron microscopy, enzyme-linked immunosorbent assay and latex agglutination for the detection of bovine rotavirus in faeces. J $S$ Afr Vet Assoc 1997, 68:93-96.

6. Ojeh CK: Isolation and propagation of bovine rotavirus in cell culture. Rev Elev Med Vet Pays Trop 1984, 37:400-405.

7. Al-Yousif Y, Anderson J, Chard-Bergstrom C, Kapil S: Development, evaluation, and application of lateral-flow immunoassay (immunochromatography) for detection of rotavirus in bovine fecal samples. Clin Diagn Lab Immunol 2002, 9:723-725.

8. Gutierrez-Aguirre I, Steyer A, Boben J, Gruden K, Poljsak-Prijatelj M, Ravnikar $M$ : Sensitive detection of multiple rotavirus genotypes with a single reverse transcription-real-time quantitative PCR assay. J Clin Microbiol 2008, 46:2547-2554.

9. Zhu W, Dong J, Haga T, Goto Y, Sueyoshi M: Rapid and sensitive detection of bovine coronavirus and group a bovine rotavirus from fecal samples by using one-step duplex RT-PCR assay. J Vet Med Sci 2011, 73:531-534.

10. Fan $Q$, Xie ZX, Lie JB, Peng YS, Deng XW, Xie ZQ, Xie LJ, Peng Y: Detection of bovine rotavirus by TaqMan based Real-time reverse transcription polymerase chain reaction assay. China Animal Husbandry \& Veterinary Medicine 2011, 38:105-108.

11. Notomi T, Okayama H, Masubuchi H, Yonekawa T, Watanabe K, Amino N, Hase T: Loopmediated isothermal amplification of DNA. Nucleic Acids Res 2000, 28:E63.

12. Xie ZX, Tang Y, Fan Q, Liu JB, Pang YS, Deng XW, Xie ZQ, Peng Y, Xie LJ, Khan MI: Rapid detection of Group I avian adenoviruses by a Loop-mediated isothermal amplification. Avian Dis 2011, 55:575-579. 
13. Saito R, Misawa Y, Moriya K, Koike K, Ubukata K, Okamura N: Development and evaluation of a loop-mediated isothermal amplification assay for rapid detection of Mycoplasma pneumoniae. J Med Microbiol 2005, 54:1037-1041.

14. Enomoto Y, Yoshikawa T, Ihira M, Akimoto S, Miyake F, Usui C, Suga S, Suzuki K, Kawana T, Nishiyama Y, et al: Rapid diagnosis of herpes simplex virus infection by a loopmediated isothermal amplification method. J Clin Microbiol 2005, 43:951-955.

15. Peng Y, Xie ZX, Lie JB, Peng YS, Deng XW, Xie ZQ, Xie LJ, Fan Q, Feng JX, Khan Ml: Visual detection of $\mathrm{H} 3$ subtype avian influenza viruses by reverse transcription loop-mediated isothermal amplification assay. Virol Jour 2011, 8:337.

16. Nemoto M, Imagawa H, Tsujimura K, Yamanaka T, Kondo, Matsumura T: Detection of equine rotavirus by reverse transcription loop-mediated isothermal amplification (RT-LAMP). J Vet Med Sci 2010, 72:823-826.

17. Desselberger U, Gray J: In Rotaviruses: methods and protocols. Edited by Gray J. Totowa, NJ: Humana Press; 2000:2. ISBN 0-89603-736-3.

18. Nagamine $\mathrm{K}$, Hase T, Notomi T: Accelerated reaction by loop-mediated isothermal amplification using loop primers. Mol Cell Probes 2002, 16:223-229

19. Rovira A, Abrahante J, Murtaugh M, Munoz-Zanzi C: Reverse transcription loop-mediated isothermal amplification for the detection of Porcine reproductive and respiratory syndrome virus. J Vet Diagn Invest 2009, 21:350-354.

20. Chen NH, Chen XZ, Hu DM, Yu XL, Wang LL, Han W, Wu JJ, Cao Z, Wang $\mathrm{CB}$, Zhang Q, et al: Rapid differential detection of classical and highly pathogenic North American Porcine Reproductive and Respiratory Syndrome virus in China by a duplex real-time RT-PCR. J Virol Methods 2009, 161:192-198.

21. Tsunemitsu H, Kamiyama M, Kawashima K, Katsuda K, Kohmoto M, Saif LJ, Shouji T, Onodera T: Molecular characterization of the major capsid protein VP6 of bovine group B rotavirus and its use in seroepidemiology. J Gen Virol 2005, 86:2569-2575.

22. Medici MC, Abelli LA, Martinelli M, Dettori G, Chezzi C: Molecular characterization of VP4, VP6 and VP7 genes of a rare G8P[14] rotavirus strain detected in an infant with gastroenteritis in Italy. Virus Res 2008, 137:163-167.

23. Tosser G, Delaunay T, Kohli E, Grosclaude J, Pothier P, Cohen J: Topology of bovine rotavirus (RF strain) VP6 epitopes by real-time biospecific interaction analysis. Virology 1994, 204:8-16.

doi:10.1186/1746-6148-8-133

Cite this article as: Xie et al:: Reverse transcription loop-mediated isothermal amplification assay for rapid detection of Bovine Rotavirus. BMC Veterinary Research 2012 8:133.

\section{Submit your next manuscript to BioMed Central and take full advantage of:}

- Convenient online submission

- Thorough peer review

- No space constraints or color figure charges

- Immediate publication on acceptance

- Inclusion in PubMed, CAS, Scopus and Google Scholar

- Research which is freely available for redistribution 